\title{
Myocardial infiltration with immature cells in hypereosinophilic syndrome
}

\author{
D. G. I. SCOTT* \\ M.B., Ch.B., M.R.C.P.
}

B. A. LeATHERDALE

M.B. B.S., B.Sc., M.R.C.P.

\author{
Department of Medicine, Dudley Road Hospital, Birmingham B18 7QH
}

\begin{abstract}
Summary
A case of hypereosinophilic syndrome is reported. Investigation failed to reveal any precipitating cause or evidence of leukaemia. Death was due to intractable cardiac failure, and post-mortem examination showed infiltration of the myocardium with sheets of immature cells. The relevance of these cells is discussed and further investigation such as cardiac biopsy is suggested for similar cases.
\end{abstract}

\section{Introduction}

The term hypereosinophilic syndrome (HES) describes a persistent marked blood hypereosinophilia associated with diffuse organ infiltration by eosinophils, in which cardiac abnormalities are prominent and cause significant morbidity and mortality. The syndrome has been previously called eosinophilic leukaemia, Löffler's fibroplastic endocarditis with eosinophilia, and disseminated eosinophilic collagen disease (Chusid et al., 1975).

\section{Case report}

A 29-year-old Irish lorry driver developed pleuritic chest pain, anorexia, haemoptysis and increasing dyspnoea 3 weeks after an influenza-like illness. He had a pyrexia of $38^{\circ} \mathrm{C}$, a tachycardia and fine crepitations in the mid and lower zones of both lungs. Chest radiography showed bilateral basal shadowing, and an electrocardiogram, widespread $\mathbf{S}-\mathbf{T}$ depression. Bronchopneumonia was suspected and antibiotic therapy started. Further investigation, however, revealed a haemoglobin of $15.1 \mathrm{~g} / \mathrm{dl}$, white cell count of $65 \times 10^{9} / 1$ of which $80 \%$ were eosinophils, $10 \%$ neutrophils and $10 \%$ lymphocytes, and a diagnosis of pulmonary eosinophilia was made.

He discharged himself against medical advice (a pattern which repeated itself on many occasions) but was re-admitted 5 days later in cardiac failure. Treatment was started with diuretics and corticosteroids because polyarteritis nodosa was suspected. During the next few weeks an apical systolic murmur was noted. His condition improved and

\footnotetext{
* Present address: Royal National Hospital for Rheumatic Diseases, Bath.
}

his eosinophil count gradually fell. He then developed small, hard, red, skin nodules on the trunk but these showed no evidence of vasculitis on histological examination. Two weeks later the onset of severe cardiac failure required intensive resuscitation. By this time his eosinophil count had risen to $110 \times 10^{9} / 1$ and his spleen was just palpable. A further episode of cardiac failure failed to respond to appropriate treatment and he deteriorated rapidly and died 3 months after the onset of the illness.

The many blood counts taken during life showed mature eosinophils with some vacuolation of the cytoplasm. At no time were blast cells seen. Polymorphs and lymphocytes were normal. Bone marrow aspiration revealed myeloid hyperplasia due to greatly increased numbers of mature eosinophils and normal numbers of granulocyte precursors. Chromosomal analysis was normal. Leucocyte alkaline phosphatase score was 113. Microbiological investigations were repeatedly normal including stool examination for ova, cysts and parasites. Aspergillus precipitins were not detected. IgE was normal. Viral titres, HAA, and tissue antibodies were negative. Liver biopsy revealed periportal eosinophilic infiltration only.

At post-mortem examination the heart was enlarged ( $600 \mathrm{~g})$ owing to biventricular hypertrophy. There were adherent mural thrombi and areas of patchy fibrosis in the endocardium and myocardium which on microscopic examination contained many eosinophils. The myocardium was infiltrated with sheets of immature cells (Figs 1 and 2), probably of the myeloid series. These cells were only present elsewhere in small numbers in the skin despite intense eosinophilic infiltration in all other tissue examined, including bone marrow, liver, testes, spleen and lungs; the coronary arteries were normal.

\section{Discussion}

There has been considerable interest recently in the effect of eosinophils on the heart (Leading Article, 1977; Oakley and Olsen, 1977; Chew et al., 1977). Chusid et al. (1975) reported cardiac involvement in approximately $95 \%$ of patients with HES. Common features were cardiac failure, mitral valve 


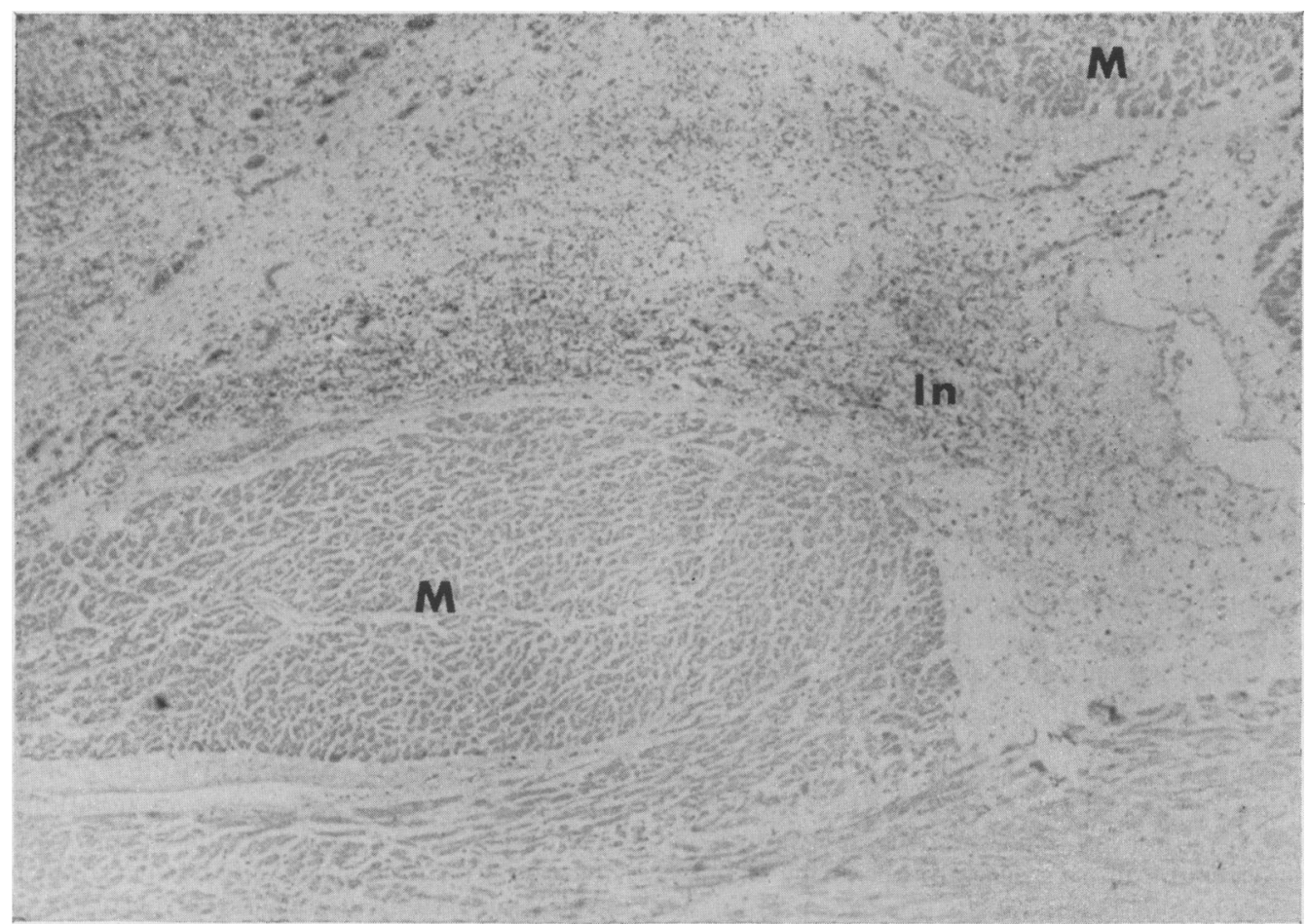

Fig. 1. Low powered view showing normal myocardium (M) with cellular infiltration (In).

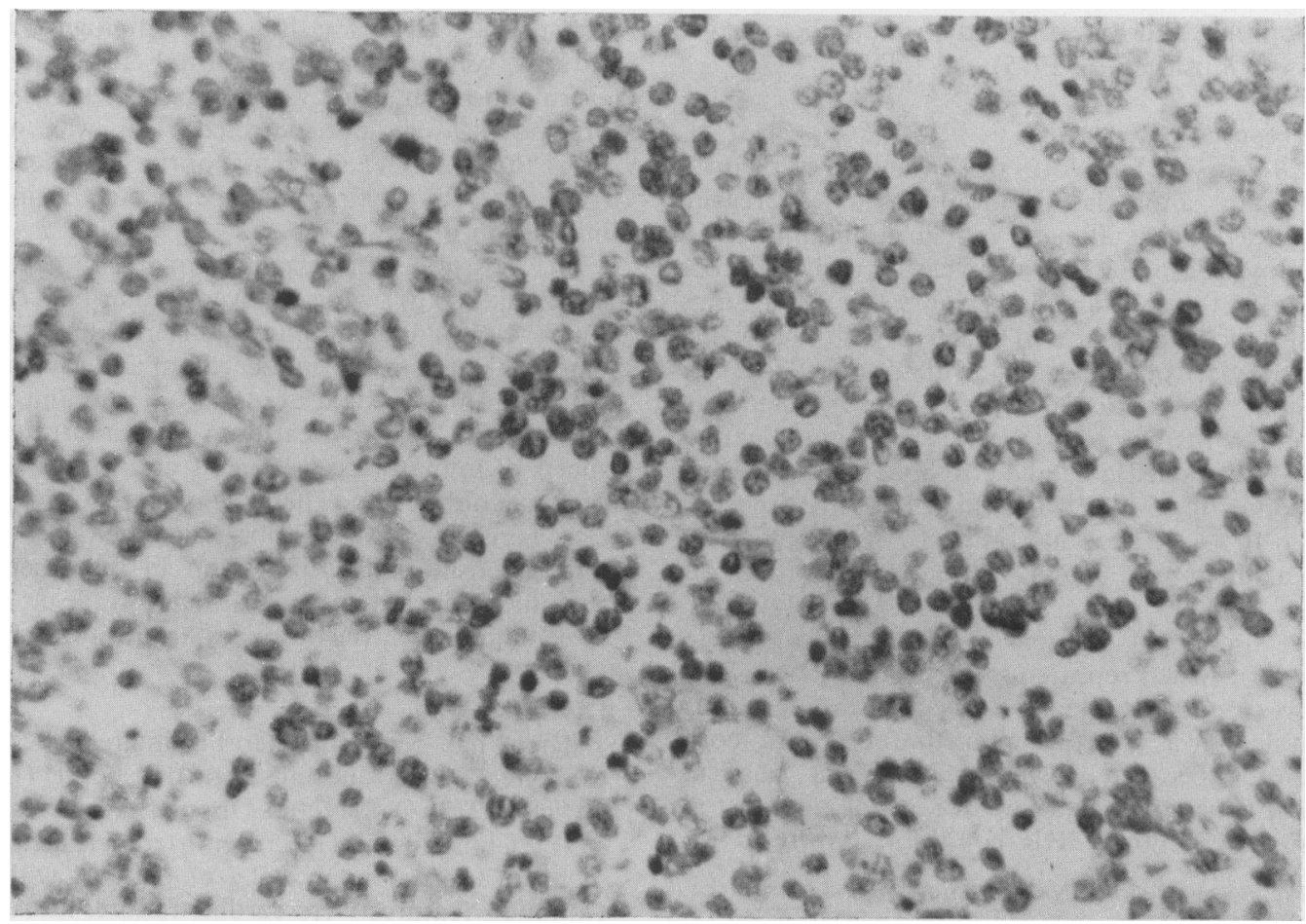

FIG. 2. High powered view of cellular infiltration showing preponderance of immature cells with mitotic activity. 
murmurs and embolic phenomena, and patients who died had subendocardial fibrosis and mural thrombi.

The present patient had an eosinophilic count of leukaemic proportions and this appears to carry a worse prognosis. The authors do not regard this as eosinophilic leukaemia, however, because blast cells were never demonstrated in either blood or bone marrow and there was no associated basophilia or chromosomal abnormality.

The tissues examined were infiltrated with mature eosinophils but the most striking features were the sheets of immature cells in the myocardium which could not be identified accurately. Such infiltration of the myocardium without other evidence of leukaemia has not been reported before and it may be that death so early in the course of the disease has shown the changes which precede the development of the classical endocardial and myocardial fibrosis and which may represent damage by 'sinister' eosinophils as recently postulated (Leading Article, 1977).
Further work is needed on eosinophil function to try to find a cause for the cardiac damage in HES. Cardiac biopsies have been obtained in only a few cases and further such studies are necessary to see if the findings described in this paper are present in other cases of this syndrome.

\section{Acknowledgments}

We wish to thank Dr S. Abraham in the Department of Pathology, Dudley Road Hospital; and Mrs C. Upton for secretarial help.

\section{References}

Chew, C.Y.C., ZIADi, G.M., Raphael, M.J., Neller, M. \& OAKLEY, C.M. (1977) Primary restrictive cardiomyopathy. Non-tropical endomyocardial fibrosis and hypereosinophilic heart disease. British Heart Journal, 39, 399.

Chusid, M.J., Dale, D.C., West, B.C. \& WolfF, S.M. (1975) The hypereosinophilic syndrome. Medicine. Baltimore, 54, 1.

Leading Article (1977) Sinister eosinophils and the heart. Lancet, i, 943.

OAKLeY, C.M. \& Olsen, E.G.J. (1977) Eosinophilia and heart disease. British Heart Journal, 39, 233. 